$\stackrel{N / 2}{N}$

Global Journals Inc

(3)

\title{
An Integrative Literature Review and Future Directions of Decent Work
}

\author{
By HU Haiming \& Yan Yan
}

Shanghai Dianji University

Abstract- The aim of decent work is to promote opportunities for women and men to obtain decent and productive work, in conditions of freedom, equity, security, and human dignity. Previous researches show that decent work has a significant impact on talent strategy on the national level, competitive advantage on organizational level and work demand meeting on the individual level. Thus, it draws much attention to home and abroad scholars. This paper reviews the previous research on decent work definition, dimensions, status quo, and related variables. Based on the research results and combined with the conservation of resource theory, this paper clarifies the definition and structure of decent work from the management perspective. From the perspective of resource gain spiral and resource loss spiral, this research proposes a theoretical framework of "perception of decent work-work attitude-work behavior". Accordingly, this study proposes suggestions for improving decent work by focusing on the definition of decent work on individual perspective, decent work scale development, and relationship among decent work perception, work attitude, and behavior in future research.

Keywords: decent work; proactive management; psychology of working theory; decent work perception; conservation of resource theory.

GJMBR-A Classification: JEL Code: M19

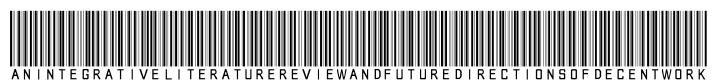

Strictly as per the compliance and regulations of:

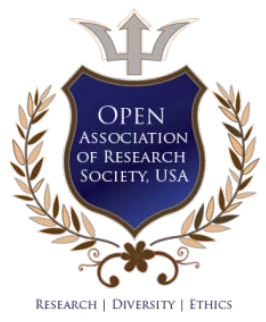

(c) 2020. HU Haiming \& Yan Yan. This is a research/review paper, distributed under the terms of the Creative Commons Attribution-Noncommercial 3.0 Unported License http://creativecommons.org/licenses/by-nc/3.0/), permitting all non-commercial use, distribution, and reproduction in any medium, provided the original work is properly cited. 


\title{
An Integrative Literature Review and Future Directions of Decent Work
}

\author{
HU Haiming ${ }^{\alpha} \&$ Yan Yan $^{\sigma}$
}

Abstract- The aim of decent work is to promote opportunities for women and men to obtain decent and productive work, in conditions of freedom, equity, security, and human dignity. Previous researches show that decent work has a significant impact on talent strategy on the national level, competitive advantage on organizational level and work demand meeting on the individual level. Thus, it draws much attention to home and abroad scholars. This paper reviews the previous research on decent work definition, dimensions, status quo, and related variables. Based on the research results and combined with the conservation of resource theory, this paper clarifies the definition and structure of decent work from the management perspective. From the perspective of resource gain spiral and resource loss spiral, this research proposes a theoretical framework of "perception of decent work-work attitude-work behavior". Accordingly, this study proposes suggestions for improving decent work by focusing on the definition of decent work on individual perspective, decent work scale development, and relationship among decent work perception, work attitude, and behavior in future research.

Keywords: decent work; proactive management; psychology of working theory; decent work perception; conservation of resource theory.

\section{INTRODUCTION}

W /ork is an important link that connects with labor organization and society. Decent work is not only closely related to the career development of workers but also of great significance in the sustainable competitive advantage of organizations and the coordinated development of society. From the perspective of individual workers, with the rapid development of China's economy, workers have shifted from their previous need for material and safety to their need for a sense of being respected, being needed and being acquired, and have put forward higher requirements for the improvement of their employability and pursuit of career development. Research shows that decent work can improve employee engagement (Qing Tao, Liu Shuang, Wang Ting, 2016) and creativity (Wang Chunguo, Chen Gang, 2018). From the perspective of enterprises, with the return of humanistic management and the advent of the new employeecentered economy, enterprises are committed to creating a good employer brand to attract more excellent employees and improve their sustainable competitive advantages. Research shows that decent

Author a o: Shanghai Dianji University, China, Shanghai, 201306. e-mail: huhaiminga@21cn.com work can effectively reduce the employee turnover rate and the number of labor disputes (Luo Yan, 2013). From the perspective of the national level, the improvement in the decent work level can promote the realization of the strategic goal of talent, and have a lasting and farreaching impact on labor productivity, household savings and consumption, and national taxation. In 2013, general secretary Xi Jinping proposed to "remove the obstacles that prevent workers from participating in the development and sharing the fruits of development, and strive to enable workers to achieve decent work." In October 2016, the outline of the 2030 plan for a healthy China stated that "promoting the construction of a healthy China is an important basis for completing the building of a moderately prosperous society in all respects and basically realizing socialist modernization. It is also a national strategy for comprehensively improving the health quality of the Chinese nation and realizing the coordinated development of the people's health and the economy and society". It can be seen that in the new era, the state attaches great importance to decent work and elevates it to the level of national strategy. To sum up, to the country, to the individual workers, to improve and enhance the decent work level of workers has become the topic of common concern of the society and individuals.

Although the state, organizations, and individual workers are well aware of the importance of decent work, they also know that to improve the decent work level of workers requires the joint efforts of the state, enterprises, and individuals at the macro, middle, and micro levels. But the complex and volatile business environment has made the path to decent work increasingly murky. Regrettably, despite some efforts by the state and companies to improve the standard of decent work for their employees, the results were not satisfactory. The polarization of wage growth between manual workers and mental workers is becoming more and more serious (Zhou Chang, Li Qi, 2017). About 70\% of knowledge workers are in the state of "overwork", and nearly $40 \%$ have entered the danger zone and are in the medium or heavy labor (Wang Dan, 2011). According to the "work happiness index survey" conducted by China human resource development network in 2004, the average working person's work happiness index is only 2.57 (out of 5 points). Studies of 2018 China office employees' health and well-being of the data showed that only $64 \%$ of the 2016 Shanghai white-collar workers 
have a healthy lifestyle, compared with $77 \%$ in 2015 to share dropped a lot. Researchers at Beijing normal university estimate that Chinese workers work an average of 2,000 to 2,200 hours a year, 17 percent more than their American counterparts. The high intensity of the work forces the staff to form a bad lifestyle but also causes the staff to pay more attention to the sense of dignity of work.

These practical problems require researchers to change their research thinking, reconstruct the connotation and dimension of decent work from a new perspective, and pay attention to the promotion strategy and path of individual-level physical labor. Since the concept of decent work was put forward in 1999, scholars have carried out researches on the definition of decent work, the construction of index system and the regional comparison of decent work from the macro level and middle level, and obtained some research results. In order to fully grasp the domestic and international research on decent work, the researchers collected and evaluated the literature. Specifically, we collected literature on the keywords "decent work" and "decent work" on the Web of Science, EBSCO, Science Direct, Pro Quest, Wiley, and China national database. By March 2019, a total of 53 English papers had been collected from SCl and SSCl journals, and 81 Chinese papers had been published in CSSCI journals. These English and Chinese papers cover philosophy, sociology, law, management, economics, and other disciplines, including 57 papers from the perspective of management. In recent years, scholars have begun to focus on the micro-level of decent work, especially in the intersection of management and psychology, which has greatly enriched the research on decent work. However, the current domestic for decent work research focus is still inadequate, and there are still some worth expanding in the study area.

First, for example, the study of decent work needs to move from institutional regulation to active management. The definition of decent work originates from the level of the system, which emphasizes improving the level of decent work through the system. However, the realization of social decent work is derived from the improvement of the individual's perception of decent work. Therefore, the implementation of decent work needs to be implemented from the level of system regulation to the level of enterprise dynamic management, and from the perspective of management science, it is necessary to realize decent work by promoting the progress of management practice. Second, the study of antecedents, outcome variables and action mechanisms of decent work mostly stay in the discussion of the relationship between variables and lacks of the theoretical basis and systematic integration. In particular, there is no in-depth theoretical explanation of the black box mechanism of the impact of decent work on individual attitudes and behaviors. For example, why does decent work affect individual attitudes and behaviors? And how does it affect individual attitudes and behavior? Therefore, it is necessary to draw lessons from relevant theories from the perspective of individuals to describe and analyze the influence mechanism and action path of decent work on individual attitudes and behaviors, to clarify the promotion path of decent work and provide references for future relevant countermeasures. Thirdly, in terms of scope, the current literature review of decent work has only been updated to 2013 (Zhou Ge, 2013). However, in recent years, the research progress of decent work at the micro-level has not been followed up, failing to present the research results and development trend of this field.

The state and society the realization of decent work not only need system design, need more active management of the enterprise. Therefore, from the perspective of management, it is particularly important to strengthen enterprises' active management ability in improving the employees' perception of decent work. However, the current research on decent work pay little attention to the active management of enterprises, and the theoretical foundation is still weak. Given this, the purpose of this paper is to explore the changes in the path of decent work promotion brought about by the change of the perspective of decent work research and to propose the framework of decent work research from the perspective of management, so as to provide reference for the research for the dynamic management of decent work at the enterprise level. In order to present the change of research emphasis on decent work comprehensively and systematically, this paper first sort out the connotation of decent work and the change of measuring tools. Furthermore, the group research on decent work in recent years is sorted out and summarized, and the influence factors, effect, and mechanism of decent work are summarized and evaluated. Finally, based on the perspective of management, on the basis of the theory of resource conservation, put forward the research framework of decent work, by the dynamic management of the enterprise of decent work ascending individual perception, thus improve the level of country, society, and to the respectable labor, for the future research provides a new perspective and direction.

\section{il. Development of the Concept of DECENT WORK}

In 1999, Juan Somavia, director-general of the international labor organization, first proposed the concept of decent work at the International Labor Conference. It refers to the promotion of decent, productive and sustainable work opportunities for men and women in conditions of freedom, equity, security, 
and human dignity, with the core of promoting the realization of rights at work, employment equality, social protection and social dialogue (ILO, 1999). The earliest research on decent work mainly USES the security perspective to define it. From the perspective of system design, this paper emphasizes that the state should issue relevant laws and regulations to ensure labor safety. However, with the development of society and the change of workers' demands, the international labor organization redefined the definition of decent work in 2015. From the perspective of equity, this definition emphasizes the protection of laborers' dignity and equal rights at work at the enterprise level. With the advance of research, scholars believe that the realization of decent work at the national level should be based on the realization of decent work at the micro level (Qing Tao et al., 2015). Since then, the definition of decent work has turned to the perspective of self-value, which emphasizes the psychological feeling of the value and dignity of work from the perspective of individual perception.

\section{a) Security Perspective}

The ILO's original definition was decent work from a security perspective. From this perspective, the state and enterprises should guarantee the income security and labor safety of laborers; that is, laborers can obtain a decent income through labor to guarantee their lives (Anker, Chernyshev, Egger, Mehran, \& Ritter, 2003). In the process of labor, workers can get adequate health protection and avoid being injured and losing the ability to work (Benach, Muntaner, \& Santana, 2007). Decent work should include reasonable income, a safe working environment, and a safe social network (Athanasou, 2010). This perspective advocates that relevant laws, regulations and policies should be formulated at the national level to ensure the safety of workers and avoid physical injury while obtaining a reasonable income, thus promoting the healthy development of human beings (Di, Cohen, Cole, \& Forman, 2015).

\section{b) Equity Perspective}

Although decency is a broad concept, including not only legal policies but also values (Putnam, 2002), it is mainly reflected in fair rights in the workplace. With the change of social environment and economic development, in 2015, the international labor organization redefined the concept of decent work (ILO, 2015). Decent work should include productive work opportunities, fair income, safety in the workplace, social protection for families, the promotion of personal development and social integration, the free expression of individual views, and the participation of all men and women in decision-making that affects their work and equality. In particular, the focus of decent work is to ensure fairness and justice (Guichard, 2013). From the perspective of human resource management, Alzola (2017) regarded decent work as the "moral rights" of employees in the workplace. Multinational companies in different institutional environments must take the moral rights of employees as the principle to be always adhered to. Based on the theories related to management, the perspective of equity emphasizes that the realization of decent work of employees requires enterprises to make management improvements, such as increasing employees' participation in organizational planning and strategic goal setting, enhancing their right of speech, voting rights and decision-making rights, and improving the efficiency of organizational communication. However, in this perspective, scholars have two opposing views. According to the optimism, the decent work proposed by the international labor organization is anti-hegemonic and infuses the postneoliberal model into the global labor rules. Thus, groups advocating equality between men and women strongly endorse decent work, which focuses on informal work and informal labor. On the contrary, pessimism condemns decent work, believing that it is consistent with neoliberal hegemonism, especially that it includes some labor laws and corporate social responsibility, which enterprises must fulfill. From the perspective of the political economy, Hauf (2015) defused two standoffs in decent work skillfully. He believed that the premise of the perspective of decent work equity is gender equality and corporate social responsibility, both of which are indispensable. Therefore, the United Nations Economics and Social Council (UNESC, 2009) proposed that enterprises should provide workers with acceptable jobs, multiple employment opportunities, good working environment, and guarantee the dignity and equal rights of workers.

\section{c) Perspective of Self-Value}

With the arrival of the odd jobs economy as well as the pursuit of a meaning laborer to work, the connotation of decent work also needs to work from the perspective of meaning and value to construct (Di \& Blustein, 2016). Occupational psychology holds that decent work should take career-related work experience as the core of self-construction (Pouyaud, 2016). Starting from the psychological feelings of workers, this perspective emphasizes that the challenges and promotion opportunities in work can realize the selfvalue and dignity of workers (Carr et al., 2013). Stein, Olle, Kellgren, and Diamonti (2016), on the basis of the Psychology of Working Theory, define decent work as stable, dignified and safe compared with dangerous work. Among them, stability, dignity, and security all come from the individual perception of the worker. Blustein et al. (2016) generally defined decent work. Therefore, Duffy et al. (2017) accurately defined decent work as a materially and spiritually safe working 
environment, disposable free working hours, organizational values consistent with family values and social values, appropriate income and medical security. From this perspective, decent work is closely related to the theory of work psychology. The theory of work psychology includes three aspects: survival and rights, social connection and self-determination. Survival and rights refer to individuals who work to earn their living and achieve their goals. Job-related factors in decent work correspond to this dimension one by one, such as job security, job stability, minimum wage, social security, paid leave, etc. Social contact refers to the contact with others and society. For example, individuals can get a sense of support and respect to work. Social contact will provide individuals with resources other than work, thus affecting the employment status in decent work. Selfdetermination refers to the individual's autonomy, ability and values related to opportunities. In decent work, employers and the government should be committed to improving the quality of employees' education, strengthening skills training and designing career, which is consistent with the ultimate goal of decent work. Compared with the perspective of safety and fairness, the perspective of self-value lays more emphasis on the subjective perception of individuals, especially the perception of the meaning and value of work. Therefore, the promotion of decent work from this perspective should start from the individual perception of workers, and improve the sense of self-value and dignity of workers by exploring the meaning and nature of work (Ferrari, 2009).

To sum up, previous studies have defined the connotation of decent work from the perspectives of security, equity and self-value (see Table 1). Due to the different research perspectives, the emphasis on improving the decent work level has shifted from the perspective of institutional norms to the perspective of enterprise dynamic management. In essence, the reason for the shift in the focus and perspective of decent work research lies in the change in workers' demand for work. From the perspective of safety, a decent work movement emphasizes that the income and safety of workers in the workplace should be guaranteed through the formulation of relevant laws and regulations at the level of system design and system specification, focusing on the material needs of workers. However, with the improvement of laws and regulations in various countries and regions, workers have put forward higher requirements for fairness and rights in the workplace, and pay more attention to the satisfaction of respect needs. Therefore, decent work from the perspective of equity lays more emphasis on the improvement of enterprise management methods and pays more attention to the protection of the rights and dignity of workers by enterprises. In recent years, with the return of humanistic management, enterprises pay more attention to the rights and happiness of workers, and the research perspective of decent work starts to shift to the perspective of self-value. For workers, they begin to pay attention to the meaning and value of work, that is, the sense of decent work at the individual level. Therefore, more emphasis is placed on the ability of active management in stimulating employees' perception of decent work. Thus it can be seen that the connotation of decent work has undergone a transformation from the perspective of security and fairness to the perspective of self-value. Accordingly, the promotion strategy of decent work shifts from the system level to the enterprise management level. This transformation process also proves that the improvement of decent work level in a country is based on the improvement of individual decent work (Qing et al., 2015). With the improvement of laws and regulations and the establishment of enterprise employer brand, future workers pay more attention to the meaning and value of work itself. Therefore, it is particularly important to define the connotation of individual decent work from the perspective of selfvalue. However, the connotation of decent work from the perspective of self-value still needs further discussion (Di \& Blustein, 2016). In fact, from the perspective of self-value, workers regard decent work as their own resources. Based on the theory of social exchange, an organization realizes its goals by utilizing the resources of its employees. Through the full use of individual resources to meet the needs of the staff, so as to obtain work reward. Therefore, from the perspective of resources, the interdependent relationship between employees and organizations is formed through matching and satisfying work resource-work needs. In view of this, this study USES the relevant definition of decent work from the perspective of self-value, and defines decent work as the overall perception of individuals under the influence of external factors such as work resources and work demand from the perspective of resources. The higher the level of decent work in the workplace, the more resources it has, and vice versa.

Table 1: Definition of the concept of decent work

\begin{tabular}{|c|l|l|l|}
\hline PERSPECTIVE & \multicolumn{1}{|c|}{ REPRESENTATIVE } & \multicolumn{1}{c|}{ VIEW } & \multicolumn{1}{c|}{ THE RESEARCH FoCUS } \\
\hline & $\begin{array}{l}\text { Anker (2003); Benach et } \\
\text { al. (2007); Di et al. } \\
\text { SECURITY } \\
\text { PERSPECTIVE); } \\
\text { (2010) }\end{array} \quad \begin{array}{l}\text { Athanasou } \\
\text { Ensure the safety of workers and } \\
\text { work safety. }\end{array}$ & $\begin{array}{l}\text { From the national level to formulate } \\
\text { relevant laws and regulations to } \\
\text { protect the labor safety. }\end{array}$ \\
\hline
\end{tabular}

This paper is funded by Shanghai Philosophy and Social Science Program (No. 2019BGL018). 


\begin{tabular}{|c|l|l|l|}
\hline FAIR VIEW & $\begin{array}{l}\text { ILO (2015); } \\
\text { UNESC (2009); } \\
\text { Alzola (2017) }\end{array}$ & $\begin{array}{l}\text { From the enterprise level, improve the } \\
\text { Protecting workers' rights, freedoms } \\
\text { and equal opportunities for men } \\
\text { and women. }\end{array}$ & $\begin{array}{l}\text { management methods, improve the } \\
\text { right speech, voting rights and } \\
\text { participation of employees, improve } \\
\text { the officiency of organizational } \\
\text { communication. }\end{array}$ \\
\hline PERSPECTIVE & $\begin{array}{l}\text { Carr (2013); Blustein } \\
\text { etc. (2016); Duffy, etc } \\
\text { OF SELF-VALUE }\end{array}$ & $\begin{array}{l}\text { Starting from the psychological } \\
\text { feelings of the workers, it is } \\
\text { emphasized that the challenges } \\
\text { and promotion opportunities in the } \\
\text { work can realize the self-value and } \\
\text { dignity of the workers. }\end{array}$ & $\begin{array}{l}\text { Starting from the individual perception } \\
\text { of laborers, the sense of self-value and } \\
\text { dignity of laborers can be improved by } \\
\text { exploring the meaning and nature of } \\
\text { work. }\end{array}$ \\
\hline
\end{tabular}

\section{ili. Measurement of Decent Work}

The measurement of decent work is the premise and foundation of the analysis of the path of decent work. Scholars have been working on the measurement of decent work. From the current research, the measurement of decent work is mainly divided into three types: the index cluster construction at the institutional level, the multi-level index construction at the macro level and the multi-dimensional index construction at the micro-level.

\section{a) Index Cluster Construction at the Institutional level}

In 2003, Anker et al. developed 63 indicators in

11 categories of decent work for the first time according to the four aspects of employment, rights, social security, and social dialogue proposed by the international labor organization. These are employment opportunities, adequate income from work and productive work, appropriate working hours, the balance between work family and personal life, jobs to be abandoned, job stability and security, equality of opportunity and treatment in employment, safe working conditions, social security, social dialogue and workers' and employers' representatives. This is the foundation work of decent work measurement. The early research on decent work focused on the use of this indicator cluster to evaluate the status of decent work in some countries and regions. In order to facilitate the operation, Cao Zhaowen (2011a) divided the 11 indicators into six categories: adequate employment opportunities, productive work, free work, equal work, safe work, and dignified work. Some scholars also use the macro indicator cluster as a tool to measure the decent work level of Denmark, South Africa, Brazil, India, and other countries (Egger, 2002; Gil, Lawrence, Fluckiger, \& Lambert, 2007; Kantor, Rani, \& Unni, 2006). By analyzing the data in the relevant statistical yearbook of China from 2000 to 2011, Lu Hong and Jin Xi (2014) found that the level of decent work in China was on the rise year by year. Further, the domestic scholar's Meng Hao, Wang Zhongzhi, Christina, Hua Jin and $\mathrm{Hu}$ Wanging decent work of China (2015) presents the regional differences, the northeast, and east decent work level is higher, low level of the western region, the horizontal center in central China, the cause of this result lies in the unbalanced regional economic development. The limitation of Anker et al. (2003) 's research lies in too many indicators and too complex operation. Bescond, Chataignier and Mehran (2003) improved the research of Anker et al. (2003) and developed seven indicators for the labor market survey: appropriate income, overtime work, unemployment rate, number of children out of school, youth unemployment rate, gender difference in labor force participation, and number of elderly people lacking social security. The survey index is more universal and operable, which is convenient for country comparison. However, due to the differences in the calculation methods of statistical indicators in different countries, the comparative study of decent work can only select those indicators with consistency; The comparability of indicators of decent work between countries is low because of the different situations in each country. Therefore, the measurement method of a macroeconomic indicator cluster has some limitations in the measurement of decent work.

\section{b) Construction of Macro, Medium and Micro Multi-level Indicators}

With the deepening of the research and the expansion of the perspective, researchers realized that the measurement of decent work only looked at the statistical indicators, which were only the results of digitization and had no practical significance (Ghai, 2003). The research on decent work should carry out index design from macroscopic, mesoscopic, and microscopic perspectives more comprehensively (Bonnet, Figueiredo, \& Standing, 2003). Furthermore, scholars use macroeconomic indicators as a reference to construct the indicator system of decent work from multiple levels. Adhikari, Hirasawa, Takakubo, and Pandey (2012) studied the decent work level and quality of working life in Nepal. It is worth noting that this study combines the concept of decent work at the macro level with the concept of quality of work and life at the micro level, which has certain enlightenment significance for the construction of multi-level indicators of decent work. Bonnet et al. (2003) proposed that the research on decent work should be carried out more comprehensively from macroscopic, mesoscopic, and 
microscopic index design. Bonnet et al. (2003) constructed an index system of labor market safety index, employment safety index, labor safety index, safety index of reproduction skills, safety index of income, and safety index of discourse right. They collected the index data of decent work from the macrolevel economic database, the mid-level enterprise labor flexibility and labor safety survey, and the micro-level citizen safety survey. On this basis, according to the strategic goal of decent work, Shen Xiaomei, and Ling Ling (2010) further decomposed the assessment indicators of decent work from three levels, namely, the government, enterprises and employees, and constructed a comprehensive and multi-level indicator system including core indicators, basic indicators, and specific indicators. Ding Yuelan and Zhou Li (2013) constructed the indicator system of decent work from the perspectives of employment, rights, social protection, and social dialogue at the government, enterprises and individuals.

The research on the construction of multi-level decent work index system makes up for the defect of the construction of macro-level index cluster and makes a more comprehensive measurement of decent work, which is convenient for the comparative study between countries and regions. However, there are some shortcomings in this kind of research: (1) due to the lack of weight design, the importance of different levels cannot be accurately measured, which makes the path of decent work more obscure; (2) these indicators are not scales, and there is no reliability and validity test, so the universality and credibility of indicators are easily challenged.

\section{c) Multi-Dimensional Construction}

With the deepening of the research, researchers gradually realized that previous researches on decent work paid too much attention to the indicators at the institutional level and neglected the individual level (Deranty \& MacMillan, 2012). In fact, whether decent work is realized or not should be a psychological construct of individual perception (Qing Tao et al., 2015). Therefore, in recent years, researchers' focus on the measurement of decent work has shifted to the multi-dimensional structure construction of decent work from the perspective of individual perception. Only when we make clear the structure of decent work, can we put forward the strategy of promoting decent work.

Webster, Budlender and Orkin (2015) first developed questionnaires at the individual level of decent work, which included 9 aspects, employment opportunity, job stability and security, income level, working hours, work-family and life balance, opportunity equity, work environment, social security and social dialogue. The items in the questionnaire are discontinuous, and the subjects only need to answer yes or no. The questionnaire is considered a pathfinder for exploring the dimensions of decent work structure. However, this study lacks the theoretical foundation in the construction of decent work structure dimension, which makes the structure dimension slightly less scientific and reasonable. At present, there are three main types of decent work scale at the individual level: (1) Ferraro, Pais, Dos and Moreira (2018). Based on the definition of decent work by the international labor organization, the scale developed 31 item scales in 7 dimensions. The seven dimensions are the basic principles and values of work, appropriate working hours, productive work, the fulfillment of citizenship, social protection, opportunity, health and safety. (2) Duffy et al. (2017) developed the decent work scale (DWS) for adults. The scale on the basis of the working theory of mind open sent a decent labor model of five dimensions: physical and spiritual security work environment, disposable free work time, is consistent with the concept of family values and social values of the organization value, the appropriate income and health care. The questionnaire was tested for consistency in sexual minority groups (Douglass, Velez, Conlin, Duffy, \& England, 2017) and cerebellar droopy groups (Tokar \& Kaut, 2018). (3) Qing Tao et al. (2016) developed a decent work perception scale based on grounded theory, taking front-line employees of enterprises as samples, which includes three dimensions: full confidence, coexistence, tolerance, respect and recognition. The scale was also adopted in the research of Wang Chunguo and Chen Gang (2018).

Besides, Xu Yan and Liu Dun (2017), based on the theory of grounded theory to enterprise managers and front-line employees as the research object, and developed a decent seven dimensions structure of labor, wage income sense of decency, job security sense of decency, working atmosphere sense of decency, the intensity of labor sense of decency, democratic participation sense of decency, career sense of dignity and status in society sense of decency. Based on the grounded theory, Mao Guanfeng, Liu Wei and Song hong (2014) developed a five-dimensional model of decent work, including work return, job position, career development, career identity and working atmosphere. Based on the maslow hierarchy of needs theory, Cong Shengmei and Zhang Zhenghe (2016) took grain farmers as the research object and studied the dimensions of decent work as survival, working conditions, social attribute, being respected and personal value. Huang Weide and Yue Linyang (2014) developed a decent work structure for knowledge workers through qualitative and quantitative analysis, including labor security, income security, job security, skill security and representation security in five dimensions.

It can be seen that the research on the structural dimension is based on the theories of psychology and management and builds the structural 
dimension of decent work from the perspective of individual perception. Qualitative research and questionnaire survey are the main methods to construct the structural dimension. From the perspective of the number of research results, the research results of decent work structure dimension are quite abundant in recent years, which may be attributed to the following reasons: (2) different countries have different social security and social protection systems, and it is difficult to standardize indicators at the macro level, while indicators at the individual level can avoid this obstacle; (3) there are differences in data sources and measurement tools in different countries, and it is difficult to standardize the macro index and middle index, while the micro index in the form of self-report can be unified in different countries and regions (Webster et al., 2015). Thus it can be seen that the structural dimension construction of decent work at the individual level is the focus of research at present.

However, there are still some shortcomings in this research: (1) in terms of connotation definition, there is still a dispute over the connotation definition of decent individual labor in the academic community, so there is no scale that has been unanimously recognized by the academic community; (2) on the content of the structural dimension, based on the different measurement subject structure dimension differences in the content aspect, the reason may be due to the laborers engaged in different types of work caused by the difference of labor demand, also may be due to the universality of the scale is not high. Therefore, the followup study needs to test the consistency of the scale in different situations. (3) in terms of theoretical basis, the current development of the scale is mainly based on grounded theory and work psychology theory. Based on different theories, there are also some differences in the structural dimension of decent work. This study holds that the scale development of decent work can use the theory of resource conservation for reference to classify the dimensions of decent work. Resource conservation theory was first proposed by Hobfoll in 1989. He believed that resources can be divided into direct resources, indirect resources, and symbolic resources. Direct resources refer to the basic material resources needed for survival, which play a direct role in the survival and health of individuals. In decent work, indicators, or dimensions related to income, safety and security can be classified as direct resources of the perception of decent work. In the theory of resource conservation, indirect resources refer to those that play an indirect role in work and life and can help individuals obtain direct resources, such as social support, marriage, and optimism. In decent work, indicators, or dimensions related to skills and work machines can be classified as indirect resources of the perception of decent work. Finally, symbolic resources refer to the symbolic resources provided by the social environment and cultural environment in which the individual lives, which have symbolic significance for obtaining direct and indirect resources. In decent work, indicators, and dimensions related to dignity, social dialogue, values, democratic participation, and so on can be classified as symbolic resources of decent work perception.

Table 2: Measures of decent work

\begin{tabular}{|c|c|c|}
\hline MEASURING TOOL & REPRESENTATIVE & DIMENSION/INDEX \\
\hline $\begin{array}{c}\text { CONSTRUCTION OF INDEX } \\
\text { CLUSTER AT THE } \\
\text { INSTITUTIONAL LEVEL }\end{array}$ & $\begin{array}{l}\text { Anker et al. (2003) } \\
\text { Bescond etc. (2003) } \\
\text { Cao Zhaowen } \\
\text { (2011a) }\end{array}$ & $\begin{array}{l}\text { Employment opportunity, the appropriate income and } \\
\text { productive work, decent balance work time, work, family and } \\
\text { personal life and should be abolished, stability, and labor } \\
\text { safety, equal employment opportunity and fair treatment, safe } \\
\text { working environment, social security, social dialogue, decent } \\
\text { work economic environment and social environment. } \\
\text { Modest incomes, overtime work, unemployment, number of } \\
\text { children out of school, youth unemployment, gender disparities } \\
\text { in labor force participation, and the number of older people } \\
\text { lacking social security } \\
\text { Adequate employment, productive work, free work, equal work, } \\
\text { safe work and dignified work. }\end{array}$ \\
\hline $\begin{array}{l}\text { MACRO, MEDIUM AND } \\
\text { MICRO MULTI - LEVEL } \\
\text { INDICATOR } \\
\text { CONSTRUCTION }\end{array}$ & Bonnet, etc. (2003) & $\begin{array}{l}\text { Macro level: the Labour market security, employment security } \\
\text { index, labor safety index, reproduction skills safety index, } \\
\text { income security, say security index. } \\
\text { Middle-level: Labour market security, employment security } \\
\text { index, labor safety index, reproduction skills safety index, } \\
\text { income security, say security index. } \\
\text { Micro level: Labour market security, employment security } \\
\text { index, labor safety index, reproduction skills safety index, } \\
\text { income security, say security index. } \\
\text { It constructs the core index, basic index and specific index } \\
\text { from the three levels of government, enterprise and employee }\end{array}$ \\
\hline
\end{tabular}

This paper is funded by Shanghai Philosophy and Social Science Program (No. 2019BGL018). 


\begin{tabular}{|c|c|c|}
\hline $\begin{array}{l}\text { MULTIDIMENSIONAL } \\
\text { CONSTRUCTION }\end{array}$ & $\begin{array}{l}\text { Shen xiaomei and } \\
\text { ling ling (2010) } \\
\text { Ding Yue-lan and } \\
\text { Zhou li (2013) } \\
\text { Duffy, etc. (2017). } \\
\text { Ferraro,etc.(2018) } \\
\text { QingTao et al. (2016) } \\
\text { Xu yan and Liu Dun } \\
\text { (2017) } \\
\text { Mao Guanfeng et al. } \\
\text { (2014) } \\
\text { Cong shengmei and } \\
\text { zhang zhenghe } \\
\text { (2016) } \\
\text { Huang Weide and } \\
\text { Yue Linyang (2014) }\end{array}$ & $\begin{array}{l}\text { The index system of employment, rights, social protection and } \\
\text { social dialogue is constructed from the three levels of } \\
\text { government, enterprises and individuals. } \\
\text { Decent work scale (DWS): a physically and mentally safe work } \\
\text { environment, disposable hours, organizational values } \\
\text { consistent with family and social values, decent income and } \\
\text { health care. } \\
\text { Decent work questionnaire (DWQ): basic principles and values } \\
\text { of work, appropriate hours of work, productive work, } \\
\text { citizenship, social protection, opportunity, health and safety. } \\
\text { Decent work perception scale: full confidence, coexistence and } \\
\text { tolerance, respect and recognition. } \\
\text { A sense of dignity in terms of wages, income, employment } \\
\text { security, working atmosphere, intensity of work, democratic } \\
\text { participation, career development and social status. } \\
\text { Job reward, job position, career development, professional } \\
\text { identity and working atmosphere. } \\
\text { Existence, working conditions, social attributes, respect and } \\
\text { personal value. } \\
\text { Labour security, income security, job security, skills security } \\
\text { and representation security. }\end{array}$ \\
\hline
\end{tabular}

\section{Research on the Group Status of DECENT WORK}

The early research on decent work is to evaluate and compare the status quo of decent work in countries and regions. However, this kind of research cannot take situational factors into account. Moreover, different groups are included in countries and regions, including both formal employment groups and informal employment groups. Due to the different demands of different groups, there are also differences in the path of decent work promotion. Therefore, in order to improve the level of decent work, scholars focused on the group study and explored the decent work situation of some groups from the perspective of the characteristics of workers.

\section{a) Research on Informal Employment Groups}

According to people club department of the human resources and social security in 2017 statistics bulletin of the thing industry development in the total employment in cities and towns and the number of people to participate in medical insurance for urban employees data estimation, informal employment in late 2017 staff more than 200 million people. Moreover, the number of this group also presents the trend of the increasing year by year. Due to the shortage of human capital and the restriction of social system, this group has been on the edge of society for a long time (Chen Jing, 2014). Therefore, it is of great significance to raise the level of decent work of this group for the whole region and country.

Working overtime is one of the important obstacles to the realization of decent work in informal employment group (Stuart, Pautz, \& Wright; 2016). He Tianping, Liu Xin and Li Huajun (2012) studied the new generation of migrant workers and found that $8.8 \%$ of them worked for more than 12 hours every day, and $71.3 \%$ of them worked for $8-12$ hours. It can be seen that the phenomenon of overtime work is common, but overtime work does not bring the new generation of migrant workers a higher salary. This conclusion has also been verified in female migrant workers and women in informal employment (Yu Mi, 2017; Li Chaoyang, 2011a). In addition, the lack of social protection is also an important difficulty in the realization of decent work. Cruz, Hardy and Sanders (2017) 's research on British strippers shows that due to the reasons for freelancing, this group lacks the necessary labor protection. They suggest improving working conditions and conditions for strippers and reducing the risk of freelancing through licensing laws and centralized organization politics. Owens and Stewart (2016) 's research on interns found that in order to gain work experience, such groups are usually free labor in enterprises, and they are faced with the dilemma of being exploited and lacking social protection. Therefore, it is suggested that the rights and protection of interns should be stipulated by law. Encourage companies to offer high-quality internship programs or training programs that are in line with educational levels. Zhang Lin and Yang Yi (2014) took domestic workers as the research object and analyzed the low level of decent work in this group, which mainly reflected four aspects: the marginalization of occupational symbol identity caused by cultural exclusion, the deprivation of employment opportunities in economic exclusion, the lack of social protection in welfare exclusion, and the weak social dialogue in relationship exclusion. In view of this, the researchers suggest that top-level design and institutional arrangements should be strengthened, policy support and implementation should be strengthened, and 
awareness and training should be improved so as to improve the decent working standards of domestic workers.

\section{b) Research on formal employment groups}

Winch enbach, Hanna and Miller (2019) found in their research on employees in tourism industry that employees in this industry have a low level of perception of decent work, which is mainly reflected in the lack of job recognition and respect, lack of job autonomy, and gender discrimination. Therefore, it is necessary to improve the sense of identity and dignity at the individual level, the organizational level, and the socioeconomic legal level in order to improve the decent work level of employees in this industry. Mehta (2016) took female employees in the ict industry in India as the research object, and studied the decent work level of this group from four aspects: employment opportunities, social security, working conditions and, social dialogue. The results showed that the job security of this group was low. For example, the contract workers in 1-3 years may be fired at any time due to poor performance and economic recession. Poor working conditions, such as short annual leave, long working hours, night shifts in some departments, high work pressure, and goaloriented work, are likely to cause mental illness and health problems. The employment security is low, such as the phenomenon of the open contract is common; Low levels of social dialogue, such as fewer workers joining unions and employers not supporting unions. Overall, decent standards of work for female knowledge workers in the sector remain low. It can be seen that operational employees pay more attention to income security, occupational skill development, occupational identity, and social recognition, while service-oriented employees pay more attention to occupational identity, customer relationship, and income security (Xu Yan, Liu Dun, 2017).

According to the survey data, about $70 \%$ of knowledge workers are in the state of "overwork", and nearly $40 \%$ have entered the danger zone and are in the medium or heavy labor (Wang Dan, 2011). In recent years, the decent working conditions of knowledge workers have attracted the attention of scholars. Teachers in colleges and universities as an object of study, according to the results of university teachers of decent work level as a whole is higher than social average (Zhao Yang li, 2011 b), but there are also some problems, such as the lack of labor remuneration, labor rights, and interests is damaged, loss of democratic rights, working pressure, fair and competitive with low income, lack of training (Zhao Yang li, 2011 b; Huang Weide, Cody, 2015). Cody (2012) measured and analyzed the decent working conditions of knowledge workers in Shanghai, and found that the decent working level of knowledge workers in Shanghai was relatively low, mainly reflected in the low level of labor security, income security and reproduction skills. If these demands are hard to meet, it will inevitably affect the decent work level of knowledge workers.

To sum up, from the perspective of practical significance, it is of great significance to explore the current situation of decent work of a group to understand the decent work level of the group and to improve the decent work situation of the group. From a theoretical point of view, the research on the status quo of decent work based on a certain group promotes relevant research on decent work. Previous research results show that researchers have found, through selfreport and secondary data, that both formal and informal employment groups have a lower level of decent work, mainly manifested in overtime work, reproduction skills security, lack of job recognition, and so on. These workers have a low sense of individual decent work. To carry out any work, the organization needs to allocate corresponding resources, and at the same time, the organization will put forward specific work needs for employees. Therefore, from the perspective of resource conservation theory, overtime labor has a low perception of direct resources in decent work, which is reflected in the lack of protection of labor rights and interests, and the mismatch between labor time and income. The guarantee of reproduction skills is the perception of the indirect resources of decent work, which is reflected in the lack of employability. Especially in the turbulent employment environment, the lack of reproduction skills will lead to the decline of employability, thus affecting the acquisition and accumulation of resources. Job recognition is a symbolic resource in decent work. When there is no job recognition, the value of employees' existing resources is difficult to be reflected, so that employees can obtain more direct and indirect resources. On the whole, the low degree of decent work perception means that individuals think that their own resources are difficult to meet the needs of work, resulting in a sense of resource scarcity, which affects work attitude and work behavior.

\section{Research on Relevant Factors of DECENT WORK}

The factors related to decent work are the core of the path analysis of decent work and the key to understanding the causes of problems in decent work. In view of this, this paper summarizes the existing researches on factors related to decent work from three aspects: antecedent variables, outcome variables and mechanism of action (see figure 1). It is found that the antecedent variables affecting decent work are mainly divided into social factors, organizational factors and individual factors. The outcome variables mainly include engagement and creativity. In terms of mechanism of action, the current research involves the research of mediating effect and regulating effect. 
a) Antecedent Variables

i. social factors

The influence of social factors on decent work is mainly reflected in cultural factors and economic factors. The individual tendencies of workers in different cultural backgrounds are different, so the influence of cultural factors should be considered in the research on decent work (Khan \& Sandhu, 2016). Compared with Bangladeshis, Chinese workers are more individualistic and long-term goal-oriented and the decent work index developed for Bangladeshi workers cannot be applied to Chinese workers. In terms of the influence of economic factors, research shows that GDP has a significant effect on the improvement of decent work, but this effect is significant on the absolute index of production, but not on the improvement of relative index (Cao Zhao Wen, 2011b). The rapid development of data in the Internet era has not only created new jobs but also brought a negative impact on the labor market. For example, the employment relationship is ambiguous, and the labor market is polarized, which makes it difficult to guarantee the rights and interests of workers and collective rights (Zhou Chang, Li Qi, 2017). Economic policy and social policy should be used in the process of improving decent work by economic means, rather than relying on economic development alone.

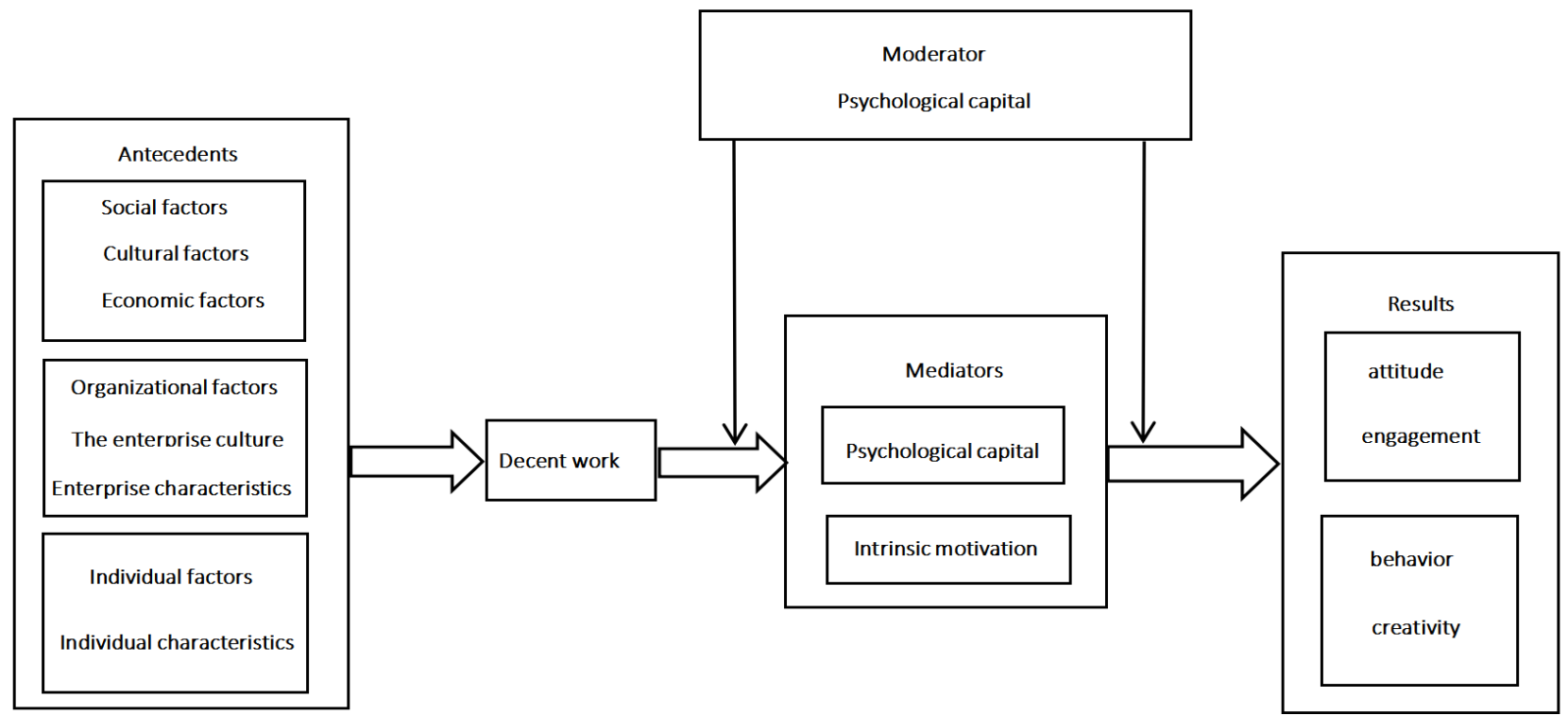

Figure 1: Research Framework of Antecedents, Results, Moderators and Mediators of Decent Work (organized by the author according to existing research)

\section{ii. Organizational Factors}

The influence of organizational factors on decent work is mainly reflected in organizational culture and corporate characteristics. Cody (2012) based on Wallach's (1983) division of organizational culture, studied its impact on decent work. The results show that bureaucratic, innovative, and supportive corporate cultures promote decent work, and this effect is achieved through the intermediary role of leading member exchange. In terms of the influence of enterprise characteristics of decent work, the degree of factor input varies with different types of enterprises. In the process of enterprise transformation from laborintensive to technology-intensive, it means more capital investment, more human capital accumulation, and improvement of management. Therefore, the capital investment of technology-intensive enterprises is the highest, so employees can feel the highest level of decent work, followed by capital-intensive enterprises and the lowest labor-intensive enterprises (Luo Yan, Li
Gang, 2015). Research on Chinese enterprises shows that the ownership nature of enterprises and the type of industry they are in have no significant impact on decent work (Luo Yan, 2013), which is in line with the goal of decent work, that is, to promote the realization of decent work for all workers in all enterprises and industries. But studies of Japanese companies show that the more foreign-owned the company, the higher the level of decent work. Because the management hopes to improve the organizational performance by improving the working conditions and working environment of employees (Kubo, 2018).

\section{iii. Individual Factors}

The research on the influence of individual factors on decent work focuses on the demographic variables and individual characteristics. Taking the cluster of macroeconomic indicators as the measurement method of decent work, the study on ordinary front-line employees shows that demographic 
factors such as age, gender and household registration have no significant influence on decent work (luo yan, li gang, 2015). (2017) of the five dimensions such as Duffy structure model for measuring tool, the study found the individual economic limitations of decent work has significant predict effect, namely the individual economic restrictions, the more respectable labor level is lower, and the relationship between economic factors and decent work levels is affected by the partial intermediary role will work (Toka \& Kaut, 2018). Grandey, Rupp and Brice (2015) found that emotional labor would increase the labor cost and thus affect the realization of decent work, especially among front-line service personnel. Therefore, organizations should abandon the emotional requirements of front-line service personnel and pay more attention to the construction of staff health and happiness atmosphere, fundamentally eliminate emotional labor.

\section{b) Results}

There are few research results on the outcome variables of decent work, and most of them are domestic research. Existing research results show that decent work has an impact on employee engagement (Qing Tao et al., 2016) and creativity (Wang Chunguo, Chen gang, 2018). Qing Tao et al. (2016) studied 1,076 front-line employees and found that the coexistence, tolerance, respect and recognition of decent work had a significant positive impact on engagement. Wang Chunguo and Chen gang (2018), taking 367 employees as samples, found that decent work had a significant positive impact on employee creativity. After controlling for the influence of demographic factors, decent work could still explain $40.8 \%$ variation in creativity.

\section{c) Moderators and Mediators}

The research on the mechanism of decent work revolves around psychological capital and motivation (Ferraro, Pais, Moreira, \&Dos, 2017; In meters, 2017; Qing Tao et al., 2016). Divided (2017), such as the study of knowledge workers, found that decent work's influence on the work motivation is accomplished by the mediating role of psychological capital, especially the decent work to external motivation of work motivation, external motivation) is accomplished by the partial mediating role of psychological capital, decent work to improve the employees' psychological capital, as a result, employees can be gained from punishment and extrinsic rewards. However, other studies have found that psychological capital plays a moderating role in the mechanism of decent work rather than an intermediary role $(Y u M i, 2017)$. In the long run, the promotion of human capital by improving the level of education and skill training of workers will help to improve the level of decent work (Reich, 2010). However, the influence of human capital on the promotion of decent work is affected by the regulating effect of psychological capital
(Yu Mi, 2017), because when human capital is relatively abundant, there is also more psychological capital, which will improve the perception level of individuals on decent work. In the research on the mechanism of motivation, Qing Tao et al. (2016) found in their research on front-line employees that intrinsic motivation plays a part in mediating between decent work and engagement. The mediating effect accounted for 0.38 percent of the total effect, that is, the mediating effect accounted for 38 percent of the total effect. It can be seen that the research on the black box mechanism of decent work is still in the initial stage, the research results are relatively scattered, and the research conclusions are still controversial. Future research can be further in-depth in this aspect.

\section{Vi. Results and Discussion}

\section{a) Integration Model Under Resource Conservation Theory}

Through literature review, we find that the research on decent work has experienced the definition of concepts from different perspectives, the construction of multidimensional dimensions, the research on the status quo of decent work aimed at groups, and the research on the relevant factors of decent work. In the past 20 years, the research on decent work has been continuously enriched and developed. With the deepening of the research, the research level of decent work has shifted from the level of system specification and system design to the level of enterprise dynamic management from the perspective of management, thus putting forward higher requirements for the diversification of research perspectives. This study USES the relevant definition of decent work from the perspective of self-value and defines decent work as the overall perception of individuals under the influence of external factors such as work resources and work demand from the perspective of resources. For the division of resources based on resource conservation theory, this study put forward a decent work and income, safety and security in the related dimension is divided into direct resources, skills and job related dimensions are classified as indirect resources, social dialogue, values, democratic participation, and related dimensions are classified as symbolic resources. In view of this, the level of decent work reflects the abundance of resources. In the theory of resource conservation, there are two spiral effects: gain spiral and loss spiral. When an individual has abundant resources, he can obtain more resources through existing resources, thus producing the aggregation effect of resources and entering the value-added spiral. When an individual lacks resources or is in danger of resource loss, it is easy to generate pressure, which will increase the risk of resource loss or even lead to resource loss, thus entering a loss spiral. 
Gain spiral

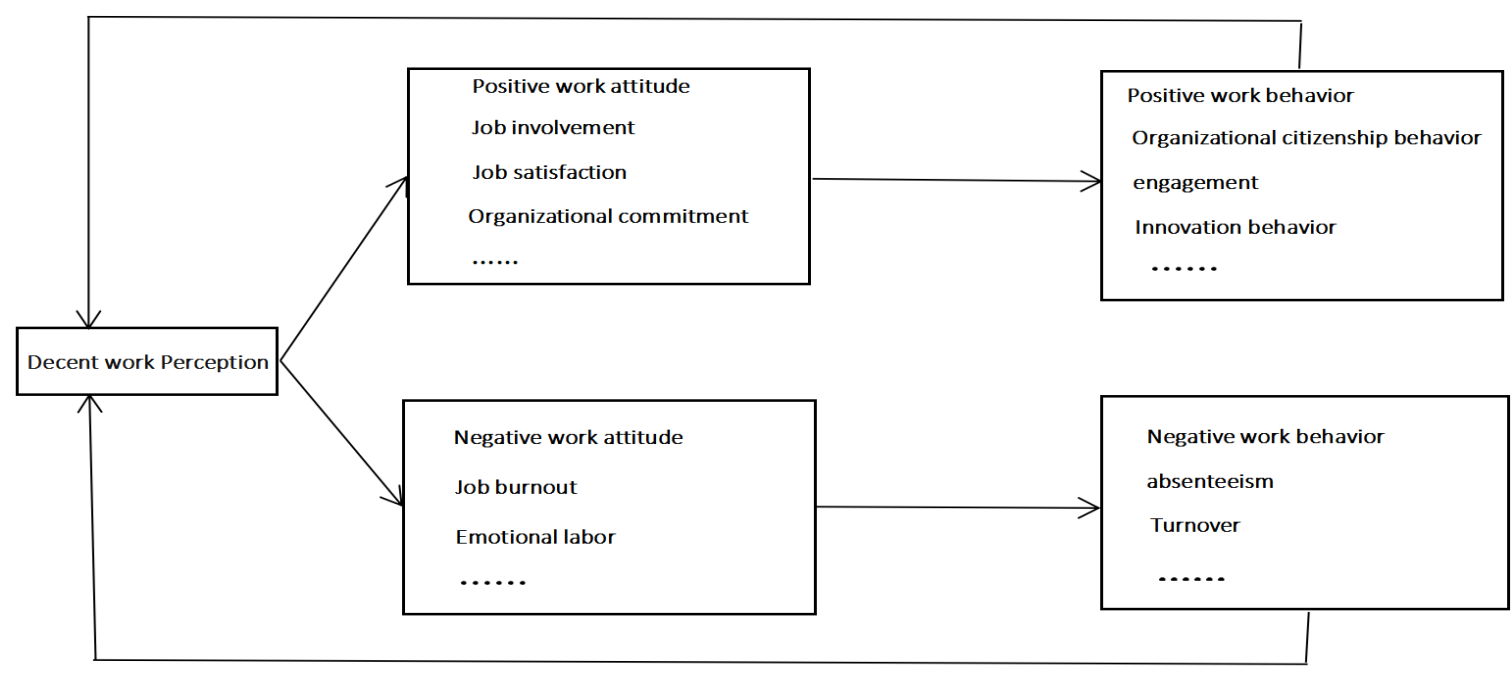

Loss spiral

\section{Figure 2: Research Framework of Decent Work from Resoure Conservation Theory}

From the perspective of resources, the knowledge, skills, social networks, and abilities of employees in the work environment are considered as individual resources. Meanwhile, the organizational support, and rewards provided by the organization to employees are also considered as individual resources. Therefore, decent work in this perspective is the individual's overall perception of work resources and work demand under the influence of external factors. On the one hand, when an individual has a high level of perception of decent work, he thinks that his knowledge, skills, ability and social network can meet the basic requirements of the job. At the same time, the working conditions, organizational support and working environment provided by the organization can ensure the smooth completion of the job. The satisfaction of work demand can bring internal and external rewards to employees, increase individual resources, and bring more resources to them, such as ability improvement, organizational recognition, and so on, so as to enter the value-added spiral of resources. Based on the perspective of positive psychology, employees with more resources are more likely to show a positive work attitude (Halbesleben \& Wheeler, 2008). They are able to make an objective judgment on the demands and difficulties of work and make an accurate prediction of possible resource losses in the process of work, thus showing higher work involvement (Gorgievski \& Hobfoll, 2008; Yuan Ling, Li Jian, Jia Lingling, 2014). On the other hand, when individuals have a low perception of decent work, they believe that they are relatively deficient in knowledge, skills and abilities and cannot meet the job requirements. In addition, the support and resources on which the organization is based are insufficient to help them complete their work tasks and meet their work needs. When individuals invest a lot of time and energy, they are unable to get the corresponding resources, which leads to psychological stress (Hobfoll, 2002) and negative emotions, such as job burnout. In a stressful environment, individuals' negative emotions will affect their work behaviors, such as declining productivity and alienation from others, which will further aggravate the loss of resources (Buchwald \& Hobfoll, 2004), thus leading to the spiral of resource loss. Based on this, this study proposes a research framework for decent work from the perspective of resource conservation theory (as shown in figure 2).

\section{b) Future Research Directions}

Since its introduction in 1999, decent work has attracted the attention of scholars at home and abroad and has accumulated abundant research achievements. However, with the deepening of the research, in recent years in the field of management science and psychology interdisciplinary there have been some research results, such as Duffy (2017) based on the working theory of mind and the development of decent employment scale, a divided (2018), such as development of decent employment scale, as well as domestic scholars Qing Tao (2016), such as Mao Guanfeng (2014), Xu Yan and Liu (2017) developed a decent work scale. It can be seen that the research perspective of decent work has gradually shifted from the level of institutional norms to the aspect of enterprise active management, and the improvement of employees' perception of decent work from the perspective of management has become a hot topic in this field. In fact, the improvement of individual decent work depends on the improvement of enterprise or organizational management ability. Therefore, from the

This paper is funded by Shanghai Philosophy and Social Science Program (No. 2019BGL018). 
perspective of management, it is an effective way to study the path of improvement of decent work in the future and the proper meaning of achieving decent work to emphasize the improvement of workers' perception of decent work by improving the dynamic management ability of enterprises and organizations. Give this, future research can be conducted from the following aspects:

First, the connotation of decent work from the perspective of individual needs to be further defined. The research on decent work from the perspective of management needs to be based on the clear definition of decent work at the individual level. From the perspective of research, the existing research defines the connotation of decent work from the perspective of safety, equity, and self-realization. Correspondingly, from the perspective of research, the security perspective is based on the definition of the national system, the equity perspective is based on the construction of decent work at the enterprise level, and the self-value perspective is based on individual perception to define the connotation of decent work. Decent work from the perspective of safety and respect derives from the definition of the international labor organization, which has been unanimously recognized by scholars. But the definition of decent work at the individual level is controversial. Carr et al. (2013) believe that decent work at the individual level should be defined in terms of the meaning and value of work, while Blustein et al. (2016), Fabio and Maree (2016) believe that dignity should be paid attention to. In fact, the two views do not conflict. Pouyaud (2016) believes that the definition of decent work should be expanded from the definition of the international labor organization to include individual perception, with special emphasis on the working conditions created by individuals in maintaining fair work opportunities and improving their employability. From the perspective of resources, this study defines decent work as the overall perception of individuals under the influence of external factors such as work resources and work demand. This concept is defined from the perspective of resources, based on individual resources and organizational resources, and from the perspective of matching between work resources and work demands. With the expansion of the research perspective, this concept needs to be further improved in future research.

Second, the universality and theoretical basis of decent work measurement need further attention. In the measurement method of decent work in the early stage, the definition of decent work is mainly adopted by the international labor organization, and some macroeconomic indicators are selected to measure the level of decent work in countries and regions. These indicators are from the national macro-level indicators, due to the differences in the way of calculation, the universality of these indicators is questionable. In recent years, researchers based on grounded theory (Qing Tao et al., 2016; Xu Yan, Liu Dun, 2017; Mao Guanfeng et al., 2014) and work psychology theory (Duffy et al., 2017) developed the decent work perception scale. However, due to the differences in research objects and theoretical basis, there are some differences in the structural dimensions of these scales. In order to improve the universality of decent work perception scale, this study considers that on the basis of the classification of resources in the theory of resource conservation, the perception of decent work of laborers is regarded as the resources possessed by laborers, and the structural dimension of individual decent work perception is divided. However, this research still needs to make further theoretical deduction on the dimension of decent work by using the theory of resource conservation, and then carry out empirical research through the normative process of scale development, and finally develop and verify the scale at the micro-level of decent work.

Thirdly, the antecedent variables of decent work should be expanded. The antecedent variables of decent work are studied from social factors, enterprise factors, and individual factors. At present, there are some empirical studies on the antecedent variables of decent work, but the research perspectives are relatively scattered, and the research conclusions are not unified. From the perspective of human resource management and labor relationship management, future research can be further expanded in terms of organizational factors and individual factors. In terms of organizational factors, the impact of organizational culture and human resource management practices on decent work has been validated. However, leadership style plays an important regulating role in HRM practice and employee perception (Zhu Fei, Hu Ruibo, 2018). Therefore, future research can incorporate leadership style into the relationship between organizational factors and the perception of decent work. On the one hand, we can explore the positive influence of leadership styles based on positive psychology, such as humorous leadership, leader member exchange, and transformational leadership on the perception of decent work. On the other hand, we can also explore the negative influence of leadership styles based on negative psychology, such as abusive leadership and authoritarian leadership, on the perception of physical labor. In terms of individual factors, the influence of demographic factors and emotional labor on the perception of decent work has been verified. However, these studies lack theoretical basis and lack of verification of the consistency of research conclusions in different situations. In the future research, the impact of individual resources on the perception of decent work can be investigated from the perspective of resource conservation theory. And vice versa. Furthermore, the leadership style in organizational 
factors and individual resources in individual factors can be integrated into the model of decent work perception for cross-layer research.

Fourth, explore the mechanism of decent work. The existing research on the mechanism of decent work has explored the "black box" of decent work from the perspective of mediation and adjustment. Research in this field has appeared in the past three years, and some research results have been obtained. With the development and improvement of the decent work perception scale, the research on the mechanism of decent work will become a hot topic in this field. In the relationship between social factors and decent work, the study found that work's intention plays an intermediary role (Douglass et al., 2017). In the relationship between decent work and attitude, studies have found that psychological capital and intrinsic motivation play an intermediary role (Qing Tao et al., 2016; Ferraro et al., 2017). These conclusions have promoted the research on the mechanism of decent work at the micro level, but there is still a lack of theoretical support, which makes the universality of the theoretical model easier to be challenged. In future research, from the perspective of resource conservation theory and from the perspective of positive psychology, we can explore whether the perception of decent work is higher when individual resources are relatively abundant. Does the perception of high decent work lead to positive work attitude (job commitment, job satisfaction, organizational commitment) and behavior (engagement, organizational citizenship behavior, innovation behavior)? Can positive work behavior achieve the accumulation of resources and value increment, so as to promote individuals to enter the epp spiral? From the perspective of negative psychology, this paper explores whether the perception of decent work is low when individual resources are relatively scarce. Does the perception of low decent work cause individuals to show negative work attitude (job burnout, emotional labor) and behavior (absence from work, resignation)? Is it easy for negative work behavior to lead to the loss of individual resources, so as to promote individuals into the loss of resources spiral? Furthermore, from the perspective of positive psychology, will positive leadership styles, such as transformational leadership and humorous leadership, have a moderating effect on the above mechanism of action? From a negative psychological perspective, will the negative leadership styles, such as abusive leadership and authoritarian leadership, have a moderating effect on the above mechanism? Therefore, future research can build models and verify them on the basis of relevant theories.

\section{References Références Referencias}

1. Cao Zhaowen. (2011a). A survey of indicators of decent work of the international Labour organization. Population and economy, 6, 57-61.

2. Cao Zhaowen. (2011b). the impact of GDP on the productivity of decent work -- an empirical analysis based on Chinese data. Research on financial and economic issues, 11, 86-90.

3. Cong Shengmei, Zhang Zhenghe. (2016). Construction of "decent work" index system for grain farmers -- based on 1,803 questionnaires in henan province. Agricultural economic problems, 7, 90112.

4. Chen Jing. (2014). Research on the construction of decent work measurement index system for urban informal employment groups. Economists, 4, 102-104.

5. Ding Yue-lan, Zhou Li. (2013). A study on the measurement index system of multidimensional decent work in China. Economics and management, 27 (10), 18-22.

6. Huang Weide, Yue Linyang. (2014). Research on decent work structure and measurement of knowledge workers -- from the perspective of individual level. Journal of east China university of technology (social science edition), 2, 47-57.

7. Huang Weid, Cody. (2015). A study on the status quo of decent work of college teachers in Shanghai. China higher education research, 11, 92-96.

8. He Tianping, Liu Xin, Li Huajun. (2012). Decent work: problems faced by the new generation of migrant workers and countermeasures. Journal of Shanxi university (philosophy and social sciences), 35 (02), 55-59.

9. Cody. (2012). Investigation on the decent working conditions of knowledge workers in Shanghai and related influencing factors (master's thesis). Shanghai: east China university of science and technology.

10. Li Chao Yang. (2011a). Research on women's decent work in informal employment. Hubei social science, 3, 38-40.

11. Li Chao Yang. (2011b). Research on women's labor rights and interests from the perspective of decent work. Gansu social sciences, 1, 13-16.

12. Luo Yan. (2013). Empirical research on factors affecting the realization of decent work--findings from micro-data of enterprises in Guangzhou, Shenzhen and Zhongshan. Academic research, 2, 76-81.

13. Luo Yan, Li Gang. (2015). Research on the realization of decent work in enterprises with different elements intensive -- a survey of high-tech zone in Shishan town, south China sea. Ningxia social sciences, 192, 87-93.

14. Lu Hong, Jin Xizai. (2014). Measurement and trend analysis of decent work level in China. Contemporary economic research, 6, 45-49.

This paper is funded by Shanghai Philosophy and Social Science Program (No. 2019BGL018). 
15. Mao Guanfeng, Liu Wei, Song Hong. (2014). A decent work perception research: scaling and inspection. Statistical observation, 14, 86-89.

16. Meng Hao, Wang Zhongzhi, Yang Jingjing, Hua Jin, Hu Wanqing. (2015). Measurement and spatial differentiation of decent work level in mainland China. Regional research and development, 34 (3), 1-6.

17. Qing Tao, Liu Shuang, Wang Ting. (2016). Research on the relationship between decent work and engagement: the role of intrinsic motivation and psychological needs. Journal of sichuan university (philosophy and social sciences edition), 206 (5), 134-143

18. Qing Tao, Zhang Lulu, Wang Ting. (2015). Measurement and effectiveness test of decent work. Economic restructuring, 4, 195-200.

19. Shen Xiaomei, Ling Ling. (2010). Analysis on the construction of multidimensional evaluation index system for decent work. China labor, 11, 23-25.

20. Wang Chunguo, Chen Gang. (2018). Decent work, innovative self-efficacy and employee creativity: the moderating effect of organizational culture in Chinese context. Management review, 30 (3), 140-149.

21. Xu Yan, Liu Dun. (2017). Reconstructing the connotation and structure of decent work -- a qualitative interview study of 271 workers in Beijing. Social science, 6, 59-70.

22. Yu Mi. (2017). The impact of human capital and social capital on the decent work of female migrant workers -- the moderating effect of psychological capital. Population journal, 39 (3), 97105.

23. Yuan Ling, Li Jian, Jia Lingling. (2014). Research on employee engagement in enterprises based on the theory of resource conservation. Journal of northeast normal university (philosophy and social sciences), 4, 95101.

24. Wang Dan. (2011). Research on overwork of knowledge workers in China. Beijing, capital university of economics and business press.

25. Zhang Lin, Yang Yi. (2014). Social exclusion analysis of the decent work deficit of domestic workers -based on a survey of Wuhan city. Hubei social sciences, 12, 52-58.

26. Zhou Chang, Li Qi. (2017). Non-standard work and decent work: labor problems caused by data and government countermeasures. Human resource development in China, 8, 156-166.

27. Zhou Ge. (2013). A recent study on foreign decent work. China labor, 3, 26-28.

28. Zhu Fei, Hu Ruibo. (2018). Research on enterprise labor relationship management in China: a review and review of research in the past 40 years of reform and opening-up, human resource development in China, 35 (10), 83-96.
29. Adhikari, D. R., Hirasawa, K., Takakubo, Y., \& Pandey, D. L. (2012). Decent work and work life quality in Nepal: an observation. Employee Relations, 34 (1), 61-79.

30. Alzola, M. (2017). Decent Work: The Moral Status of Labor in Human Resource Management. Journal of Business Ethics, 147 (3), 1-19.

31. Anker, R., Chernyshev, I., Egger, P., Mehran, F., \& Ritter, J. (2003). Measuring decent work with statistical indicators. International Labor Review, 142 (2), 147-178.

32. Athanasou, J. A. (2010). Decent work and its implications for careers. Australian Council for Educational Research, 19 (19), 36-44.

33. Benach, J., Muntaner, C., \& Santana, V. (2007). Employment conditions and health inequalities: Final report to the $\mathrm{WHO}$ by the $\mathrm{CSDH}$. Retrieved March 19, 2018, from http:// cdrwww.who.int/ entity/social_determinants/resources/articles/ emconet who report.pdf.

34. Bescond, D., Chataignier, A., \& Mehran, F. (2003). Seven indicators to measure decent work: an international comparison. International Labor Review, 142 (2), 179-211.

35. Blustein, D. L., Olle, C., Kellgren, A. C., \& Diamonti, A. J. (2016). Decent work: A psychological perspective. Frontiers in Psychology, 7, 1-10

36. Bonnet, F., Figueiredo, J. B., \& Standing, G. (2003). A family of decent work indexes. International Labor Review, 142 (2), 213-238.

37. Buchwald, P., \& Hobfoll, S. E. (2004). Burnout in the conservation of resources theory. Psychologie in Erziehung Und Unterricht, 51 (4), 247-257.

38. Carr, S. C., Thompson, L. F., Reichman, L. F., Mcwha, W., Marai, I., \& Maclachlan, M. (2013). Humanitarian work psychology: Concepts to contributions. Asia Pacific Journal of Human Resources, 46 (3), 303-315.

39. Cruz, K., Hardy, K., \& Sanders, T. (2017). False selfemployment, autonomy and regulating for decent work: improving working conditions in the UK stripping industry. British Journal of Industrial Relations, 55, 274-294.

40. Deranty, J. P., \& Macmillan, C. (2012). The ILO's decent work initiative: Suggestions for an extension of the notion of "Decent Work". Journal of Social Philosophy, 43 (4), 386-405.

41. Di, R. E., Cohen, J. E., Cole, D. C., \& Forman, L. (2015). Competing conceptualizations of decent work at the intersection of health, social and economic discourses. Social Science \& Medicine, 133, $120-127$.

42. Di, F. A., \& Blustein, D. L. (2016). Editorial: From meaning of work to meaningful lives: The challenges 
of expanding decent work. Frontiers in Psychology, 7, 1-2.

43. Douglass, R. P., Velez, B. L., Conlin, S. E., Duffy, R. D., \& England, J. W. (2017). Examining the psychology of working theory: Decent work among sexual minorities. Journal of Counseling Psychology, 64 (5), 550-559.

44. Duffy, R. D., Allan, B. A., England, J. W., Blustein, D. L., Autin, K. L., \& Douglass, R. P. (2017). The development and initial validation of the decent work scale. Journal of Counseling Psychology, 64 (2), 206-221.

45. Egger, P. (2002). Perspectives: Towards a Policy Framework for Decent Work. International Labor Review, 141 (1), 161-174.

46. Fabio, A. D., \& Maree, J. G. (2016). Using a transdisciplinary interpretive lens to broaden reflections on alleviating poverty and promoting decent work. Frontiers in Psychology, 7, 1-14.

47. Ferrari, L. E. (2009). Decent employment and subjectivity in the workplace: Notes for an agenda of labor policies in citizenship terms. Orientat. Soc, 9, 1-8.

48. Ferraro, T., Pais, L., Moreira, J. M., \& Dos, S.N.R. (2017). Decent Work and Work Motivation in Knowledge Workers: The Mediating Role of Psychological Capital. Applied Research in Quality of Life, 13 (2), 501-523.

49. Ferraro, T., Pais, L., Dos, S.N.R., \& Moreira, J. M. (2018). The decent work questionnaire: Development and validation in two samples of knowledge workers. International Labor Review, 157 (2), 243-265.

50. Ghai, D. (2003). Social Security: Learning from Global Experience to Reach the Poor. Journal of Human Development, 4 (1), 125-150.

51. Gil, P., Lawrence, R. J., Fluckiger, Y., \& Lambert, C. (2007). Decent Work in Santo Andre: Results of a Multi-method Case Study. Habitat International, 32 (2), 172-179.

52. Gorgievski, M. J., \& Hobfoll, S. E. (2008). Work can Burn Us Out or Fire Us Up: Conservation of Resources in Burnout and Engagement. New York: Nova Science.

53. Grandey, A. A., Rupp, D., \& Brice, W. N. (2015). Emotional labor threatens decent work: A proposal to eradicate emotional display rules. Journal of Organizational Behavior, 36 (6), 770-785.

54. Guichard, J. (2013). Career guidance, education, and dialogues for a fair and sustainable human development. In Inaugural Conference of the UNESCO (Chair) of Lifelong Guidance and Counseling, University of Wroclaw, Wroclaw, Poland.

55. Halbesleben, J. R. B., \& Wheeler, A. R. (2008). The Relative Roles of Engagement and Embeddedness in Predicting Job Performance and Intention to Leave. Work and Stress, 22 (3), 242-256.

56. Hauf, F. (2015). The paradoxes of decent work in context: a cultural political economy perspective. Global Labor Journal, 6 (2), 138-155.

57. Hobfoll, S. E. (2002). Social and Psychological Resources and Adaptation. Review of General Psychology, 6 (4), 307-324.

58. International Labour Organization. (2015). Decent Work and the 2030 Agenda for Sustainable Development. Retrieved March 18, 2018, from http://www.ilo.org/global/topics/sdg-2030/lang-en/index.htmILO.

59. Kantor, P., Rani, U., \& Unni, J. (2006). Decent Work Deficits in Informal Economy. Economic and Political Weekly, 5 (27), 2089-2097.

60. Khan, A., \& Sandhu, M. (2016). Benchmarking national culture and decent work practice indicators in project-based industry: Lessons from United Arab Emirates. Benchmarking: An International Journal, 23 (3), 490-518.

61. Kubo, K. (2018). The effect of corporate governance on firms' decent work policies in Japan. Asia Pacific Journal of Human Resources, 56 (4), 450-473.

62. Mehta, B. S. (2016). A decent work framework: Women in the ICT sector in India. Information Development, 32 (5), 1718-1729.

63. Owens, O., \& Stewart, A. (2016). Regulating for decent work experience: Meeting the challenge of the rise of the intern. International Labor Review, 155 (4), 678-709.

64. Pouyaud, J. (2016). For a psychosocial approach to decent work. Front Psychology, 7, 422.

65. Putnam, H. (2002). The collapse of the fact/value dichotomy and other essays. Cambridge: Harvard University Press.

66. Reich, R. (2010). The challenge of decent work. International Labour Review, 141 (1-2), 115-122.

67. Stuart, F., Pautz, H., \& Wright, S. (2016). Decent Work for Scotland's Low-Paid Workers: A job to be done. University of the West of Scotland Warwick Institute for Employment Research. DOI:10.21201/2016.619740. 66.

68. Tokar, D. M., \& Kaut, K. P. (2018). Predictors of decent work among workers with Chiari malformation: An empirical test of the psychology of working theory. Journal of Vocational Behavior, 106, 126-137.

69. Webster, E., Budlender, D., \& Orkin, M. (2015). Developing a diagnostic tool and policy instrument for the realization of decent work. International Labor Review, 154 (2), 123-145.

70. Winchenbach, A., Hanna, P., \& Miller, G. (2019). Rethinking decent work: The value of dignity in tourism employment. Journal of Sustainable Tourism, 3, 1-18. 